\title{
Anisotropic and Unilateral Damage Application to Concrete
}

\author{
Y.Labadi $^{1,}$ O. Bélaidi Chabane Chaouche ${ }^{2,3}$, NE. Hannachi ${ }^{2}$ \\ ${ }^{1}$ CFAI de l'Aube, 12 rue Québec 10430 Rosières Près Troyes,France, \\ ${ }^{2}$ Laboratoire lamons, Faculté du Génie de la Construction Département de Génie Civil, \\ Université Mouloud Mammeri de Tizi_ouzou, Algérie, \\ ${ }^{3}$ Université de Technologie de Troyes,France \\ Email :bel_ouar@yahoo.fr, labadi_y@yahoo.fr,hannachina@yahoo.fr
}

\begin{abstract}
A theoretical model is presented suitable for the description of the damaging process in brittle materials. The model is based on damage mechanics: it features two second order symmetric damage tensors, representative of surface damage induced by tensile and compressive strains activates at different orientations to the principal strain directions, according to the sign of the principal strain which attains a damage threshold, and a scalar variable representative of volumetric damage. In this model, two separate damage variables, one for tension and the other for compression, allow to model the non-symmetric behaviour and the unilateral effect. Damage activation is governed by two different loading functions evolving with nonreciprocal hardening and softening. The capabilities of the model in describing the mechanical response of material elements subjected to non-proportional stresses are illustrated.
\end{abstract}

Keywords: concrete, non linear behaviour, damage, anisotropy, unilateral effect, numerical aspects.

\section{Introduction}

It is well known that the deformation of most engineering materials is often accompanied by irreversible changes in their internal structures. The nucleation and the growth of distributed microscopic cavities and cracks do not only induce the occurrence of macro-cracks, but also lead to the deterioration of material properties due to internal microstructural changes. Therefore, understanding and knowledge of the damaging process and its effects on the macroscopic behaviour of materials are very important prerequisites for accurate analysis of structural integrity of practical problems. An approach to these problems can be provided by the recently developed theory of continuum damage mechanics (CDM), which involves irreversible micro structural changes implicitly. Several CDM models have been proposed for brittle materials. For example, the Chow and Yang model 1991 [1], is based on the hypothesis of damage surface that is similar to the yield function in plasticity theory and uses one scalar valued internal variable to represent the damage state. The Chaboche model [2] assumes anisotropic damage basically and introduces tensorial damage variables. Therefore, it can be 
considered that there exists a relationship between small cracks (damage) and strain direction. However, a detailed method to apply this model to anisotropic damage in any direction is still under development. Moreover CDM theories, which incorporate vectors [3], scalars [4], second-order tensors [5, 6], and fourthorder tensors [7] have been proposed. But these theories show either a discontinuous stress-strain response when the unilateral condition takes place or an unacceptable non-symmetric elastic behaviour for some loading conditions. In this paper, we attempt to describe the non-linear elastic constitutive equation using CDM and evaluate the structural integrity of brittle material components by the damage parameter introduced in this type of theory.

Concrete structures exhibits essentially elastic-brittle behaviour, the failure is accompanied by local loss in stiffness and strength, as a consequence of the concurrent coalescence and growth of micro cracks: a phenomenon which is usually defined as 'damage'. The complexity of microscopic mechanisms, which occur in concrete during the damage process, includes notably the formation of cracks in tension and the closure of cracks in compression, with possible friction between the crack lips.

In concrete materials the inelasticity is generally associated with irreversible thermodynamics process involving elastic degradation. Strength and stiffness degradation can be effectively modelled in the framework of CDM: isotropic damage models with a single damage variable [8] or a tension damage variable and a compression damage variable [3,9], anisotropic damage models $[6,10,11$,$] ,$ to cite a few.

The aim of the paper is to propose a thermodynamically consistent model, which accounts for some anisotropy induced by damage, and which includes unilateral effects related to crack closure. Attention is paid to limiting the complexity of the model, and especially the number of parameters, in order to make the model a viable candidate for practical engineering computations.

The present work is an extension of the model proposed to simulate the nonlinear mechanical behaviour of brittle materials, and successfully applied to structural analysis of concrete structures [12].

\section{The damage model}

\subsection{Generality}

Introduced in 1958 by Kachanov [13] for creep failure of materials under uniaxial loads, and proposed a creep damage evolution model. Later Rabotnov (1969) [14] improved Kachanov's creep model by introducing an extra coefficient to show that the damage rate is influenced more strongly by the degree of damage than by the global mechanical behavior. Continuum damage mechanics has been applied in the 1980 for simulating the non linear behaviour of concrete $[8,15,16]$. Thermodynamics of irreversible processes gave the framework to formulate the adapted constitutive laws (e.g. Lemaitre and Chaboche 1985) [17]. Considering the material as a system described by a set of variables and a thermodynamic potential, constitutive laws are systematically derived along with conditions on 
the kinematics of damage. However, an adequate choice of the potential and of the damage variable (scalar, tensor, etc.) remains to be made. Several anisotropic damage models have already been proposed by Dragon and Mroz 1979 [18], Mazars and Pijaudier-Cabot 1989[19], Fichant and al. 1999[20]. Possible applications cover also dynamic problems [19, 21], porous materials [22], and chemical damage [27]. A recent literature review on damage mechanics can be found in Pijaudier-Cabot 2000 [30].

\subsection{Elasticity modelling}

The model is formulated within a strain space framework. In order to make the subsequent implementation in finite element code easier, Helmotz's strain based free energy has been chosen. The Cauchy strain tensor, $\underline{\varepsilon}$, will be split into a volumetric part, $\varepsilon_{v}$, and a deviator part $\underline{\mathrm{e}}$, so that:

$$
\underline{\varepsilon}=\varepsilon_{v} \cdot \underline{1}+\underline{e}
$$

The stress-strain relation:

$$
\underline{\sigma}=2 \mathrm{G} . \underline{e}+\mathrm{K} \cdot \operatorname{Tr}[\underline{\varepsilon}] \cdot \underline{1}
$$

Where $\mathrm{K}$ and $\mathrm{G}$, are the bulk and shear modulus of the undamaged material, respectively.

The free energy is considered as sum of two contributions:

- a surface contribution : $\rho \psi_{\text {surf }}=\operatorname{G.Tr}(\underline{\text { e.e. }})$

- a volumetric contribution : $\rho \psi_{\text {vol }}=\frac{1}{2} \mathrm{~K} \cdot \operatorname{Tr}^{2}[\underline{\varepsilon}]$

$\rho$ is the material density and $\rho \psi_{e l}$ is the Helmotz's free energy.

\subsection{Elasticity coupled with anisotropic damage}

To traduce the damage, two independent variables are chosen:

- a scalar variable $\delta$ representing the volumetric damage of material, i.e. the reduction, in effective volume of a damaged unit element volume compared with a virgin one. The material behaviour is due to the effect of a strong hydrostatic pressure applied to the micro porous structure of the concrete.

- a second order symmetric damage tensor $\underline{\mathrm{D}}$. This tensor is meant to be representative of 'surface damage', i.e. the reduction in effective area of surface elements with different orientations from the undamaged to the damaged state.

The damage and the inelastic strains evolve simultaneously. These micro voids are the cause of the inelastic strains. 
The thermodynamic forces associated to $\underline{\mathrm{e}}, \underline{\mathrm{D}}$ and $\delta$ have as expressions:

$$
\begin{gathered}
\underline{\sigma}=2 \mathrm{G} \cdot \operatorname{Tr}\left[(\underline{1}-\underline{\mathrm{D}})^{1 / 2} \cdot \underline{.} \cdot(\underline{1}-\underline{\mathrm{D}})^{1 / 2}\right]+\mathrm{K} \cdot(1-\delta) \operatorname{Tr}[\underline{\varepsilon}] \underline{1}+\frac{1}{2}\left(2 \mathrm{G} \beta(\underline{\mathrm{D}} \cdot \underline{\mathrm{D}})+\gamma \mathrm{K} \delta^{2} \underline{1}\right) \\
\underline{\mathrm{Y}}_{\mathrm{D}}=\mathrm{G} \underline{\mathrm{e}} \cdot \underline{\mathrm{e}}-2 \beta \mathrm{G}[\underline{\mathrm{D}} \cdot \underline{\mathrm{e}}+\underline{\mathrm{e}} \cdot \underline{\mathrm{D}}] \\
\mathrm{Y}_{\delta}=\frac{1}{2} \mathrm{KTr}^{2}[\underline{\varepsilon}]-\gamma \mathrm{K} \delta \operatorname{Tr}[\underline{\varepsilon}]
\end{gathered}
$$

Since $\underline{Y}_{D}$ and $Y_{\delta}$ are positive functions, the damage growth laws are such that $\dot{\mathrm{D}} \geq 0 \quad$ and $\quad \dot{\delta} \geq 0$

From Relation [3] one deduces the inelastic stress which is written:

$$
\underline{\sigma}_{\mathrm{an}}=\frac{1}{2}\left(2 \beta \mathrm{G}(\underline{\mathrm{D}} \cdot \underline{\mathrm{D}})+\gamma \mathrm{K} \delta^{2} \underline{1}\right)
$$

$\beta$ and $\gamma$ are two new intrinsic parameters of material

We can observe that the total stress is divided into two parts

- an isotropic contribution, relating to the volumetric damage variable $\delta: \gamma \mathrm{K} \delta^{2} \underline{1}$

- an anisotropic contribution, relating to the surface damage variable $\underline{\mathrm{D}}: 2 \beta \mathrm{G}(\underline{\mathrm{D}} \cdot \underline{\mathrm{D}})$

\subsection{Unilateral damage modelling}

This unilateral damage effect usually leads to complex models when damage anisotropy is considered, one writes:

$$
\underline{\mathrm{e}}=\underline{\mathrm{e}}^{\mathrm{t}}+\underline{\mathrm{e}}^{\mathrm{c}}
$$

In the same way one postulates the existence of two independent internal variables, $\underline{D}^{t}$ and $\underline{D}^{c}$ for traction and compression respectively. Allowing for unilaterality, the stress-strain relationship of the material:

$$
\begin{gathered}
\underline{\sigma}=2 \mathrm{G} \cdot \operatorname{Tr}\left[\left(1-\underline{\mathrm{D}}^{\mathrm{t}}\right)^{1 / 2} \cdot \underline{\mathrm{e}}^{\mathrm{t}} \cdot\left(\underline{1}-\underline{\mathrm{D}}^{\mathrm{t}}\right)^{1 / 2}\right]+\mathrm{G} \cdot \operatorname{Tr}\left[\left(1-\underline{\mathrm{D}}^{\mathrm{c}}\right)^{1 / 2} \cdot \underline{\mathrm{e}}^{\mathrm{c}} \cdot\left(\underline{1}-\underline{\mathrm{D}}^{\mathrm{c}}\right)^{1 / 2}\right] \\
+\mathrm{K} \cdot(1-\delta) \operatorname{Tr}[\underline{\varepsilon}] \cdot \underline{1}
\end{gathered}
$$


Derivation of equation with respect to the damage variables yields the damage driving forces conjugate to and:

$$
\underline{Y}_{D}^{t}=-\frac{\partial(\rho \psi)}{\partial \underline{D}^{t}}=G \cdot \underline{e}^{t} \cdot \underline{e}^{t}, \underline{Y}_{D}^{c}=-\frac{\partial(\rho \psi)}{\partial \underline{D}^{c}}=G \cdot \underline{e}^{c} \cdot \underline{e}^{c}, Y_{\delta}=-\frac{\partial(\rho \psi)}{\partial \delta}=\frac{1}{2} K \cdot \operatorname{Tr}^{2}[\underline{\varepsilon}]
$$

\section{$3 \quad$ Damage evolution laws}

\subsection{Evolution law of tensile damage}

So that the law of evolution is written:

$$
D_{i}^{t}=1-\left[\left(\frac{e_{D 0}}{e_{i}^{t}}\right) \exp \left[-b\left(e_{i}^{t}-e_{D 0}\right)\right]\right]
$$

$\mathrm{b}$ is a material parameter driving the slope of the softening branch.

\subsection{Evolution law of Compressive damage}

Compressive damage in a particular direction is considered only as a consequence of the tensile behaviour of the material and, is taken equal to a function of the state of tensile along the orthogonal directions $[6,20]$; one uses a law power of the form:

$$
D_{i}^{c}=\left(\frac{D_{j}^{t}+D_{k}^{t}}{2}\right)^{\alpha}
$$

$\alpha$ is a material parameter

\subsection{Evolution law of Volumic damage}

One proposes an exponential form for the evolution of the volumetric damage:

$$
\delta=1-\left[\left(\frac{\varepsilon_{\mathrm{D} 0}}{\langle\operatorname{Tr}[\varepsilon]\rangle}\right) \exp \left[-\mathrm{b}\left(\langle\operatorname{Tr}[\underline{\varepsilon}]\rangle-\varepsilon_{\mathrm{D} 0}\right)\right]\right]
$$

\section{$4 \quad$ Numerical results}

\subsection{Uniaxial tension test}

We present here, the response of concrete representative volume element (RVE) submitted to a uniaxial tension under controlled displacement. The calculation is carried out under the hypothesis of two dimensional plane strains. 
The material parameters used for the analysis are: (The data of the tested specimen are the following)

$\mathrm{E}=20000 \mathrm{MPa}, \quad v=0.2 . \quad \mathrm{f}_{\mathrm{t}}=2.5 \mathrm{MPa} \quad \mathrm{f}_{\mathrm{c}}=25 \mathrm{MPa}$

$\mathrm{G}_{\mathrm{f}}=0.05 \mathrm{Nmm} / \mathrm{mm}^{2} \quad \varepsilon_{\mathrm{Do}}=0.0001$

Hypothetical values of: $\beta=8.10^{-4} \quad \gamma=-3.10^{-4}$

The numerical results obtained from the simulation of the uniaxial tensile test are reported below

The response in tension is represented on the Fig.1. The model returns the principal characteristics of the material.

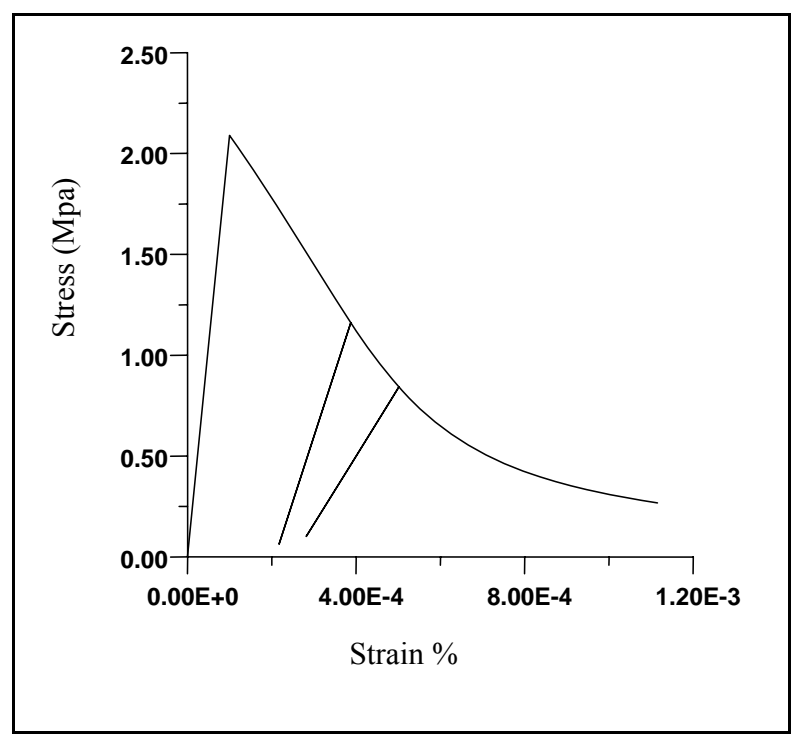

Figure 1: Tension test.

- a loss of stiffness beyond a certain stress point due to damage which is strongly anisotropic due the directionality of the defects (induced anisotropy);

- a permanent or irreversible strains with the loss of material stiffness (wich are due to growth of damage).

\subsection{Response of the model under Compressive loadings}

A unit volume of material is loaded in uniaxial compression under controlled displacement.

The analysis is performed at the material level.

The material parameters used for the analysis are:

$$
\begin{array}{llll}
\mathrm{E}=20000 \mathrm{MPa}, & v=0.2 & \mathrm{f}_{\mathrm{t}}=2.5 \mathrm{MPa} & \mathrm{f}_{\mathrm{c}}=25 \mathrm{MPa} \\
\mathrm{G}_{\mathrm{f}}=0.05 \mathrm{Nmm} / \mathrm{mm}^{2} & \varepsilon_{\mathrm{Do}}=0.0001 & &
\end{array}
$$


In Fig. 1 the stress-strain plot in uniaxial compression is shown. The asymmetric behaviour in compression typical of brittle materials is correctly described. The response of the model in terms of stress versus the longitudinal and transverse strain is represented on the Fig. 2 and Fig.3. One can observe that the model is able to describe the volumetric response of the material satisfactorily.

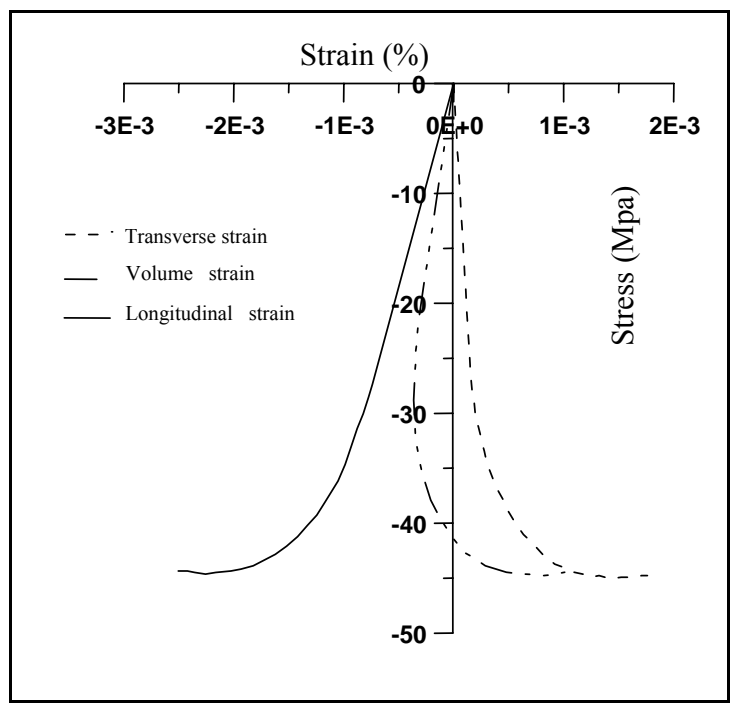

Figure 2: Compression test.

We represent below in Fig.3, the evolution of the surface damage and volume damage.

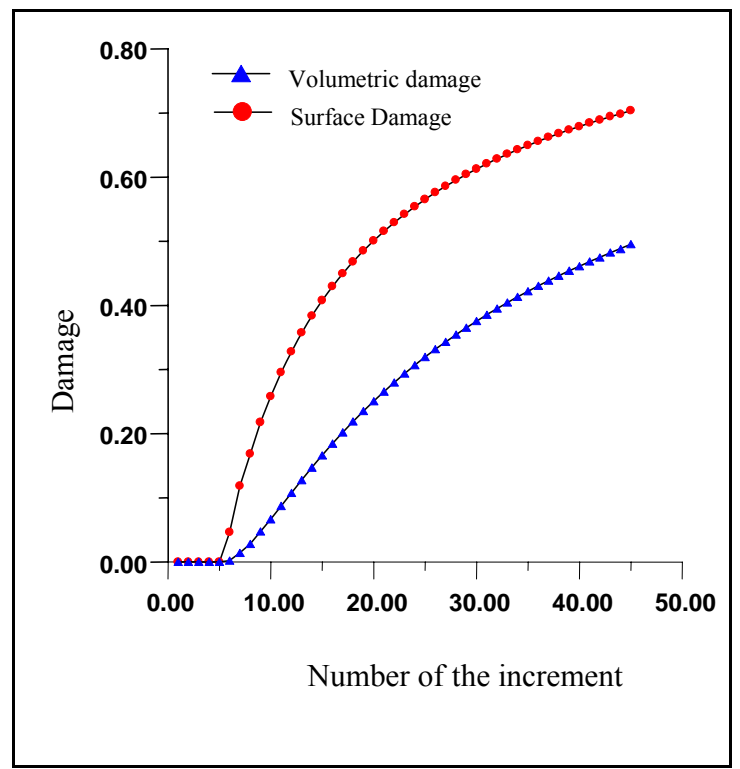

Figure 3: Surface and volumetric damage evolution. 


\subsection{Response of an RVE under cyclic loading}

For instance, Fig. 4 show the numerical simulation of a uniaxial tension followed by compression on one element:

The dissymmetric behavior between traction and compression and a softening behavior during traction and compression is captured by the model. A Fig. 4 show that the unilateral condition applied to the anisotropic damage model preserve the continuity of the response and gives a stiffness recovery with the change from the damaging loading in traction to a compression loading.

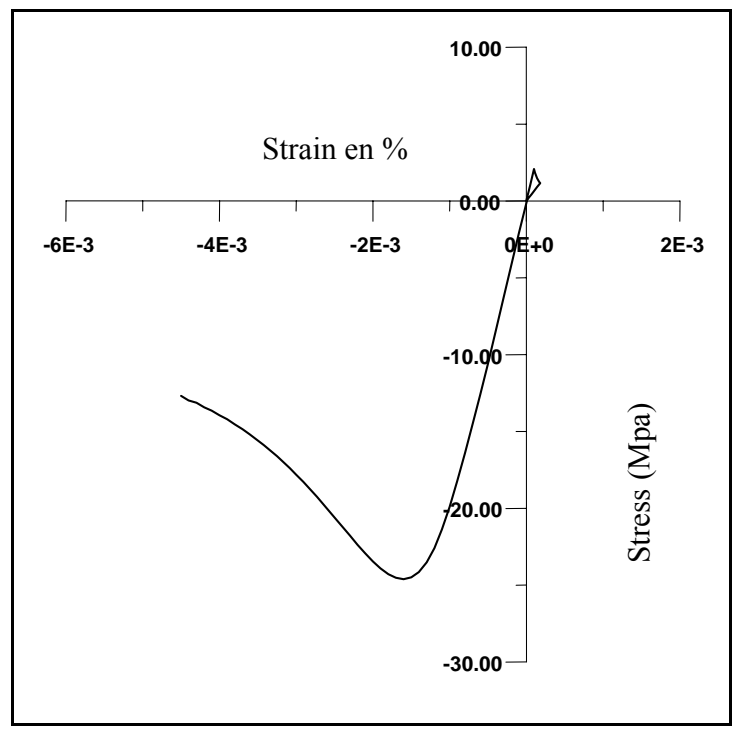

Figure 4: Unilateral effect.

\section{Conclusion}

A new anisotropic damage model is proposed for brittle materials such as concrete. The model is formulated in the framework of the continuum damage mechanics. A second-rank symmetric tensor is used to characterize material surface damage due to oriented microcracks; the volumic damage is characterized by a scalar damage variable.

This anisotropic model is combined with a unilateral condition in order to take into account the crack closure phenomenon and elastic moduli recovery.

The validity of the model is tested through numerical predictions in various loading conditions. The overall performance of the model is evaluated. The proposed damage model is capable of capturing several aspects of the nonlinear behaviour of brittle solids, namely, the damage-induced anisotropy, the unsymmetric behaviour in tension and compression, the 'unilateral' behaviour of the material. 
Extensions are still required to incorporate in the model important phenomena, such as the hysteresis loops at fixed level of damage during cyclic loadings, which were neglected in the present version.

\section{Acknowledgement}

This work must much with the framing of my reader, Mister Professor N.E.Hannachi. I particularly make a point of thanking it for his moral support and his constant availability in my connection. I am particularly very grateful to Mr Y.Labadi to have assisted me and have directed along this work. Its councils were to me of a great utility.

\section{References}

[1] C.L. Chow, F. Yang, On one-parameter description of damage state for brittle material, Eng. Fract. Mech., 40(2): 335-343, 1991.

[2] J.L. Chaboche, P.M. Lesne, J.F. Maire, Continuum damage mechanics, nisotropy and damage deactivation for brittle materials like concrete and ceramic composites, Int. J. Damage Mech., 4(1): 5-22. 1995

[3] D. Krajcinovic, G.U. Fonseka, The continuous damage theory of brittle materials, parts II and I. J. Appl. Mech. ASME, 48: 809-82, 1981.

[4] P. Ladeveze, J. Lemaitre, Damage effective stress in quasi-unilateral material conditions, IUTAM Congress, Lyngby, Denmark, 1984.

[5] C. Cordebois, F. Sidoroff, Endommagement anisotrope en élasticité et plasticité, Journal de Mécanique appliquée, 25: 45-60,1979.

[6] S. Ramtani, Contribution à la modélisation du comportement multiaxial du béton endommagé avec description de l'effet unilatéral, thèse de doctorat de l'université Paris VI, France, 1990.

[7] Ju, L.W., On energy-based coupled elastoplastic damage theories: constitutive modelling and computational aspects, Int. J. Solids Struct., 25(7): 803-833, 1989.

[8] J. Lemaitre, J. Mazars, Application de la théorie de l'endommagement au comportement non linéaire et à la rupture du béton de structures, Annales de l'ITBTP, 401, 1982.

[9] C. Comi, A non local model with tension and compression damage mechanisms, European Journal of Mechanics: A/Solids, 20: 1-22, 2001.

[10] F. Ghrib, R. Tinawi, Non linear behaviour of concrete dams using damage mechanics, Journal of Engineering Mechanics, 121(4): 513-527, 1995.

[11] F. Ragueneau, J. Mazars, Ch. La Borderie, Damage model with frictional sliding, Contributions towards structural damping for concrete structures, Revue Européenne des Eléments Finis, 10: 1-15, 2001.

[12] Y. Labadi, N.E. Hannachi, Non linear damage behavior of concrete structures, Can. J. Civ. Eng., Vol. 32: 765-774, 2005. 
[13] Ch. La Borderie, Phénomènes unilatéraux dans un matériau endommageable: modélisation et application à l'analyse des structures en béton, Thèse de doctorat, Université Paris 6, 1991.

[14] Y.N. Rabotnov, Creep rupture, Proc. XII Int. Appl; Mech. Conference, Edited by M. Htenyi and H. Vicinti, Stanford University, pp. 342-349, 1968.

[15] D. Krajcinovic, Constitutive equations for damaging material, J. Appl. Mech. ASME, vol. 50,355-360, 1983.

[16] P. Ladevèze, Sur une théorie de l'endommagement anisotrope, Int. Report n. 34, Laboratoire de Mécanique et Technologie, Cachan, France, 1983.

[17] J. Lemaitre, J.L Chaboche, Mécanique des matériaux solides, DunodBordas Ed. Paris, France, 1985.

[18] A. Dragon, Z. Mroz, A continuum model for plastic-brittle behaviour of rock and concrete, Int. J. Engng. Sci., vol. 17, pp. 121-137, 1979.

[19] J. Mazars, G. Pijaudier-Cabot, Continuum damage theory: Application to concrete, J. Engrg. Mech., ASCE, 115(2): 114-122, 1989.

[20] S. Fichant, Ch. La Borderie, G. Pijaudier-Cabot, Isotropic and anisotropic descriptions of damage in concrete structures, Int. J. Mech. of Cohes.-Frict. Mat, vol. 4, pp. 339-359, 1999.

[21] F. Ragueneau, Ch. La Borderie, J. Mazars, Damage Model for Concrete like Materials Coupling Cracking and Friction, Contribution towards Structural Damping: First Uniaxial, Application, Mechanics Cohesive Frictional Materials, vol.5, pp 607-625, 2000.

[22] G. Pijaudier-Cabot, N. Burlion, Damage and localisation in elastic materials with voids, Int. J. Mech. of Cohes.-Frict. Mat., vol. 1, pp. 129-144, 1996.

[23] S. Fichant, G. Pijaudier-Cabot, Ch. Laborderie, Continuum damage modelling: Approximation of crack induced anisotropy, Mechanics Research Communications, 24(2): 109-114, 1997.

[24] J. Mazars, Application de la mécanique de l'endommagement au comportement non linéaire et à la rupture du béton de structure, Thèse de Doctorat, Université Paris 6, France, 1984.

[25] R.H.J Peerlings, R. de Borst, W.A.M. Brekelmans, J.H.P. Vree, Gradient enhanced damage for quasi-brittle materials, Int. J. Num. Meth. Engrg, vol. 39, pp. 3391-3403, 1996.

[26] B. Gérard, G. Pijaudier-Cabot, Ch. La Borderie, Coupled Diffusion-Damage Modelling and the Implications on Failure due to Strain Localisation, Int. J. Solids \& Structures, Vol. 35, pp. 4107-4120, 1998.

[27] G. Pijaudier-Cabot, Z.P. Bazant, Nonlocal damage theory, J. of Engrg. Mech. ASCE, vol.113, pp. 1512-1533, 1987.

[28] L.M. Kachanov, Times of the rupture process under creep conditions, ISV. ARad. SSSR Otd. Teckh. Nauk, 8:26-31 in Russian, 1958.

[29] G. PIJAUDIER-CABOT, Continuum Damage Modelling, Special number of the French Review of Civil engineering, summer School ALERT Constitutive Modelling of Geomaterials, pp. 33-58, 2000. 